\title{
Auditing of Power Quality on Building G5 of Universitas Muhammadiyah Yogyakarta
}

\author{
Agus Jamal $^{* 1}$, Slamet Suripto ${ }^{1}$, Rama Okta Wiyagi ${ }^{1}$, Dimas Bangkit Wijayanto ${ }^{1}$, Yessi Jusman ${ }^{1}$, \\ Teguh Iman Prasetyo ${ }^{2}$ \\ ${ }^{1}$ Department of Electrical Engineering, Faculty of Engineering, Universitas Muhammadiyah Yogyakarta \\ Jl. Brawijaya, Tamantirto, Kasihan, Yogyakarta, Indonesia \\ ${ }^{2}$ Production on the Job Trainer and Competence Assessor, Petroleum Development Oman \\ Muscat, Sultanate of Oman \\ *Corresponding author, e-mail: agus_jamal@umy.ac.id
}

\begin{abstract}
Universitas Muhammadiyah Yogyakarta, as an educational institution, indeed uses the building as a supporting facility for all activities carried out. In each of the reviews, these activities, of course, use of electrical energy, but not infrequently the electrical energy used exceeds the limits of the reasonableness of the resulting use in financial swelling. An energy audit is an activity carried out periodically to determine the amount of energy consumption, irregularities in the system, and load imbalances that cause power losses in a building. These parameters can be obtained by measuring on the SDP panel using a power quality analyzer with IEEE 59-1992 as a obtained reference to the results of the average voltage fluctuations are still within the safe limits determined by PLN items, i.e., from 198 to 231 volts. THDv is still within the safe limit under 5\%, as well as for the THDi is also still within the safe limit of tolerance of $15 \%$. As a result of harmonic disturbances and load imbalances in the building G5 in 2018, the caused losses of power losses that need to be borne by Universitas Muhammadiyah Yogyakarta in the amount of $R p$ 9,210,133.09.
\end{abstract}

Keywords: Energy Audit, Electrical Power Quality, Voltage Harmonics, Current Harmonics

\section{Introduction}

The population density increases every year, is directly proportional to the energy needs of both industries, companies, other institutions as well as the burden of housing, because energy is one important factor for the operation of electronic devices that are used [1]. To overcome these problems, the Indonesian government launched a massive project to increase the number of power plants are planned to reach $35,000 \mathrm{MW}$ which is expected energy needs and welfare of the people can is covered [2].

For the efficient use of energy is often used method of Conservation of Energy [3]. Energy conservation is increasing energy efficiency used by consumers or commonly called the energy saving process is one method in energy audit, which is a method for calculating the level of energy consumption of a building or buildings [4]-[5]. Then the results of an energy audit will be compared with the Indonesian National Standard that applies hereinafter sought a solution if the result data from Standard Energy Audit exceeds applicable Energy Indonesia, which means that there is wastage of energy used.

Universitas Muhammadiyah Yogyakarta, as a higher educational institution in, indeed uses the building as a supporting facility for all activities carried out. One of the building in the university is Building G5. Building $G$ is one of the buildings used for teaching media both classroom and laboratory practice for students of Engineering, Medicine, Agriculture, Nursing. Building G consists of 6 buildings, i.e., building G1 used to nursing department, building G2 is used for medicine department, building G3 for agriculture department, 
building G4 used for pharmaceuticals department, building G5 for both civil and electrical engineering departments, and building G6 for mechanical engineering department. When viewed department from the $G$ functions as a laboratory building, of course, very much attached load as well as a lighting system and the air system is always active to support the activities that occur, thus allowing their wastefulness in energy use.

Several studies have linked use as reference in this study, such as Windiastuti (2015), conducted a study on electrical power quality audit on building of Electrical Engineering Department of UGM in 2015. Results of the study found that the quality of the electrical power in the building of Electrical Engineering Department in overall was quite good, with the results of the analysis conducted varying voltage unbalance values obtained from 0.147 to 1.085; the voltage varies from $201 \mathrm{~V}$ to $228 \mathrm{~V}$; THD voltage varies from $1.83 \%$ to $2.11 \%$; THD current values varies from $0.00 \%$ to $76.86 \%$ and the value of the power factor varies from 0.29 to 1.00 [6].

Ginting, et al. (2013) conducted a case study on the effect of neutral harmonic to the flow distribution transformer in Sari Mutia Hospital, Medan, the North Sumatera. The results of these case studies stating current THD in transformer Sari Mutiara Hospital exceed the standards by which the phase R of $2.172 \%$, phase S amounted to $11.533 \%$ and the phase $\mathrm{T}$ of $2.746 \%$, while the THD voltage does not exist beyond the standard IEEE 519, in addition to the large currents order 0 in phase $R$ (3.487 A), S (6.761 A), T (3.316 A), and phase to neutral (13.561 A) [7].

Mulyana (2018) in his article entitled "Measuring Voltage and Current Harmonics Power in Building the ICT Directorate of Education University of Indonesia," said that the results of the study showed that in general the content of harmonic voltage and electric current in the ICT Building UPI above the permitted standard. With the details are current harmonic content (\%THDi) was $26.1 \%-45.2 \%$ at peak hours and $23 \%-31.3 \%$ at less busy hours for the standard $15 \%$. While the content of harmonic voltage (\%THDV) in the ICT Building at rush hour is in the range of $5.5 \%-8.3 \%$ and at less busy hours $<5 \%$ at the standard $5 \%$ [8].

Based on related research and energy requirements in Building G5, the authors have been conduct the research of power quality auditing on the building. The building is a part of the laboratory facility in Universitas Muhammadiyah Yogyakarta, Indonesia.

\section{Methods}

Flowchart for the research is presented in Fig. 1.The steps undertaken to conduct this research can be obtained as a flow chart as follows:

1. First study

The initial study is the first step to obtain primary data and secondary data by means of direct survey and visual observations to a data collection briefly and interviewed the manager of the building G5 and users such as employees, technicians, agency assets, and the designer of the building.

\section{Literature review}

Book study is a step to obtain information to support theories that are used for research, audit method to be executed, and matters related to the research. The information obtained can be used as guidelines or standards in performing quality audits electric power as well as the existing problems in the field. A literature study can be printed books, ebooks, journals, research thesis which is similar as well as from faculty or technicians who provide relevant information about energy audit.

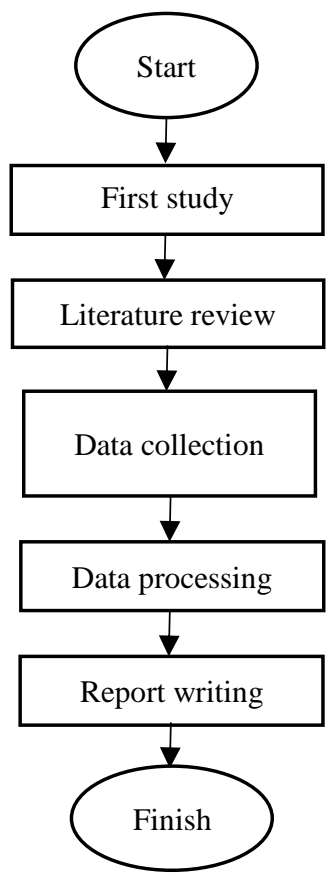

Fig. 1. Research flow chart

\section{Data collection}

There are several steps in collecting data, among others: The data collection form: single line diagram of the building, the building SDP panel measured G5 by requesting secondary data to UMY and measurement Assets Bureau SDP panel. SDP panel measurements per day for two weeks with one day later retrieval of the day off (Monday, 
Wednesday, Friday, and a week in the first week and then on Tuesday, Thursday, Saturday in the next weeks) later in the recap then calculated the value of the power losses then analyzed and solved.

\section{Data processing}

Data processing is divided into two methods:

a. Calculation of the Used Energy

- The calculation of the average value of each parameter SDP panel for one week.

- The calculation of the value of power losses (power losses) resulting from the current imbalance and harmonic distortion.

- Calculation large losses due to imbalance currents and harmonic distortion.

b. Analysis Calculation Results

- Analysis of the average value of voltage, current, THDv, THDi and power factor.

- The analysis of power losses result from an imbalance current and harmonics.

- Analysis considerationthat can be implemented in conservation of electrical energy with a more efficient method.

\section{Preparation of reports}

Preparation of the report is the final step in an energy audit which basically recaps the results of historical data, the installed load measurement, calculation of the value of power losses and losses due to harmonics and imbalance charges as well as the analysis of measured data beforehand. This report can then be used as guidelines to make energy savings that can be done based on field conditions.

\section{Results and Discussion}

\section{III.1. Measurement of SDP Panel in Building G5}

Power installed in the building broke into the commercial electricity users with the power of social rates of more than $200 \mathrm{KVA}$. SDP panel measurement data Monday on May 21, 2018. Based on the results of measurements that have been made in the SDP panel, then using the average value of the parameters can be tabulated as shown in Table 1 .

Based on the measured data SDP panel on Monday can be seen that the average voltage value is still within the limits permitted the up and down limit is $5 \%-10 \%$ of the value of the standard voltage between $220 \mathrm{~V}$ or $198-231 \mathrm{~V}$, where the measurement results in the can namely $226.47 \mathrm{~V}$ on phase $\mathrm{R}, 230.85 \mathrm{~V}$ the $\mathrm{S}$ phase and the phase $230.88 \mathrm{~V} \mathrm{~T}$. While the results of measurements of electrical current imbalance loads. This is indicated by the difference in current value large enough perphase also the neutral current value on a scale approaching the value of current in phase R.

Harmonic disturbance that occurred on Monday can be seen in Table 1 where the value\% THDv the SDP panel G5 buildings in the range of 2:23\% (phase T) - 2:39\% (phase R). Based on the IEEE standards set a maximum limit for the value of $\%$ THDv is 5\%, so it can be said that the\% THDv G5 buildings meet the standard. As for the value\% THDi on the G5 building SDP panel in the range of 9:41\% (phase R) - $11.86 \%$ (S phase). Based on the IEEE standards set value\% THDi value should not exceed $15 \%$ this year, so we can say that\% THDi G5 buildings meet the standard.

Power factor measured at the SDP panel of building G5 Universitas Muhammadiyah Yogyakarta to phase R, S, T measured 0896, 0.95, 0874. The value is above the standard value of which amounted to PLN 0.85. Unbalanced Voltage (unbalanced loads) can still be said to be safe because the IEEE standard limits defined for Unbalanced Voltage value is $2 \%$.

TABLE I

The Average Value Measurement of SDP Panel in G5 Building for Monday

\begin{tabular}{|c|c|c|c|c|c|}
\hline \multirow{2}{*}{ No. } & \multirow{2}{*}{ Parameter } & \multicolumn{4}{|c|}{ Monday } \\
\hline & & Phase R & Phase S & Phase T & Neutral \\
\hline 1 & Frequency $(\mathrm{Hz})$ & & 50.01333 & & \\
\hline 2 & Voltage (V) & 226.47 & 230.85 & 230.88 & \\
\hline 3 & Voltage THD (\%) & 2.3875 & 2.2958 & 2.2333 & \\
\hline 4 & Electric current (A) & 26.758 & 42.317 & 40.117 & 23.621 \\
\hline 5 & Electric current THD (\%) & 94.125 & 11.858 & 11.225 & \\
\hline 6 & Active Power (W) & 5605.895 & 9251.671 & 8242.803 & \\
\hline 7 & Reactive power (Var) & 2127.830 & 3000.470 & 3906.390 & \\
\hline 8 & Apparent power (VA) & 6008.386 & 9735.045 & 9165.153 & \\
\hline 9 & Power factor & 0.896 & 0.95 & 0.874 & \\
\hline 10 & V Unbalanced IEEE (\%) & & 12.708 & & \\
\hline 11 & A Unbalanced IEEE (\%) & & 38.625 & & \\
\hline
\end{tabular}


TABLE II

The Average Value Measurement of SDP Panel in G5 Building for Tuesday

\begin{tabular}{rlcccc}
\hline \hline \multirow{2}{*}{ No. } & \multicolumn{1}{c}{ Parameter } & \multicolumn{4}{c}{ Tuesday } \\
\cline { 3 - 6 } & & Phase R & Phase S & Phase T & Neutral \\
\hline 1 & Frequency (Hz) & 224.7 & 229.4 & 230 & \\
2 & Voltage (V) & 2.238 & 2.183 & 2.096 & \\
3 & Voltage THD (\%) & 31.533 & 42.85 & 51.313 & 29.125 \\
4 & Electric current (A) & 9117 & 11.63 & 11.64 & \\
5 & Electric current THD (\%) & 6583.59 & 9255.97 & 10662.4 & \\
6 & Active Power (W) & 2279.7 & 3085.4 & 4366.9 & \\
7 & Reactive power (Var) & 6986.1 & 9768.43 & 11581.6 & \\
8 & Apparent power (VA) & 0.92 & 0.94 & 0.90 & \\
9 & Power factor & & 1.450 & & \\
10 & V Unbalanced IEEE (\%) & & 37.395 & & \\
11 & A Unbalanced IEEE (\%) & &
\end{tabular}

TABLE III

The Average Value Measurement of SDP Panel in G5 Building for Wednesday

\begin{tabular}{clcccr}
\hline \multirow{2}{*}{ No. } & \multirow{2}{*}{ Parameter } & \multicolumn{4}{c}{ Wednesday } \\
\cline { 2 - 5 } & & Phase R & Phase S & Phase T & Neutral \\
\hline 1 & Frequency (Hz) & 223.9 & 229 & 229.7 & \\
2 & Voltage (V) & 2.238 & 2.183 & 2.083 & \\
3 & Voltage THD (\%) & 32.11 & 39.85 & 52.94 & 32.3 \\
4 & Electric current (A) & 10.53 & 13.01 & 10.17 & \\
5 & Electric current THD (\%) & 6822.3 & 8548.8 & 11085 & \\
6 & Active Power (W) & 2020 & 2907 & 4316 & \\
7 & Reactive power (Var) & 7122.7 & 9052.8 & 11955 & \\
8 & Apparent power (VA) & 0.95 & 0.94 & 0.90 & \\
9 & Power factor & & 16.125 & & \\
10 & V Unbalanced IEEE (\%) & & 34.112 & \\
11 & A Unbalanced IEEE (\%) & &
\end{tabular}

SDP panel measurement data on Tuesday, May 29, 2018. Based on the results of measurements that have been made in the SDP panel, then using the average value of the parameters can be tabulated as shown in Table 2.

Based on the measured data of SDP panel on Tuesday can be seen that the average voltage value is still within the limits permitted the limit up and down is $+5 \%$ and $-10 \%$ of the rated voltage of between 198- standard $220 \mathrm{~V}$ or $231 \mathrm{~V}$, where the measurement results in to the $224.7 \mathrm{~V}$ on phase R, $229.4 \mathrm{~V}$ at $\mathrm{S}$ phase and $230 \mathrm{~V}$ at phase Q. While on the results of measurements of electrical current imbalance loads. This is indicated by the difference in current value large enough per-phase also the neutral current value on a scale approaching the value of current in phase $R$.

Harmonic disturbance that occurred on Tuesday, can be seen in Table 2 where the value\% THDv the SDP panel G5 buildings in the range of $2.10 \%$ (phase T) $-2.24 \%$ (phase R). Based on the IEEE standards set a maximum limit for the value of $\%$ THDv is 5\%, so it can be said that the\% THDv G5 buildings meet the standard. As for the value of \%THDi on the G5 building SDP panel in the range of $9.12 \%$ (phase $\mathrm{R}$ ) to $11.64 \%$ (phase $\mathrm{T}$ ).

Based on the IEEE standards set value\% THDi value should not exceed $15 \%$ this year, so we can say that $\%$ THDi G5 buildings meet the standard.

Power factor measured at the building SDP panel G5 Universitas Muhammadiyah Yogyakarta to phase R, S, T measured are 0.92, 0.94, and 0.9. The value is above the standard value of which amounted to PLN 0.85. Unbalanced Voltage (unbalanced loads) can still be said to be safe because the IEEE standard limits defined for Unbalanced Voltage value is $2 \%$.

SDP panel measurement data Wednesday on May 23, 2018. Based on the results of measurements that have been made in the SDP panel, then using the average value of the parameters can be tabulated as shown in Table 3 .

Based on the measured data of SDP panel on Wednesday can be seen that the average voltage value is still within the limits permitted the limit up and down is $-10 \%$ and $+5 \%$ of the rated voltage of between $198 \mathrm{~V}$ and the standard of $220 \mathrm{~V}$ or $231 \mathrm{~V}$, where the measurement results in to the $223.9 \mathrm{~V}$ on R-phase, $229 \mathrm{~V}$ at phase $\mathrm{S}$ and phase T. While 229.7 
$\mathrm{V}$ on the results of measurements of electrical current imbalance loads. This is indicated by the difference in current value large enough per-phase also the neutral current value on a scale approaching the value of current in phase $R$.

Harmonic disturbance that occurred on Wednesday can be seen in Table 3 where the value\% THDv the SDP panel G5 buildings in the range of 2:08\% (phase T) - 2:24\% (phase R). Based on the IEEE standards set a maximum limit for the value of $\% \mathrm{THDv}$ is $5 \%$, so it can be said that the $\%$ THDv G5 buildings meet the standard. As for the value\% THDi on the G5 building SDP panel in the range of 10:17\% (phase T) - 13:01\% (S phase). Based on the IEEE standards set value\% THDi value should not exceed $15 \%$ this year, so we can say that $\%$ THDi G5 buildings meet the standard.

Power factor measured at the building SDP panel G5 Universitas Muhammadiyah Yogyakarta to phase R, S, T measured $0.95,0.94,0.9$. The value is above the standard value of which amounted to PLN 0.85. Unbalanced Voltage (unbalanced loads) can still be said to be safe because the IEEE standard limits defined for Unbalanced Voltage value is $2 \%$.

Measurement data SDP panel on Thursday, May 31,2018 . Based on the results of measurements that have been made in the SDP panel, then using the average value of the parameters can be tabulated as shown in Table 4.

Based on the measured data on Thursday SDP panel can be seen that the average voltage value is still within the limits permitted the limit up and down is $-10 \%$ and $+5 \%$ of the rated voltage of between 198 - standard $220 \mathrm{~V}$ or $231 \mathrm{~V}$, where the measurement results in to the $225.3 \mathrm{~V}$ on phase $\mathrm{R}$, 229.7V the S phase and the phase $231.2 \mathrm{~V}$ T. While the results of measurements of electrical current imbalance loads. This is indicated by the difference in current value large enough per-phase also the neutral current value on a scale approaching the value of current in phase $T$.

Harmonic disturbance that occurred on Thursday can be seen in Table 4 where the value\% THDv the SDP panel G5 buildings in the range of $2.12 \%$ of (phase T) $-2.27 \%$ (phase R). Based on the IEEE standards set a maximum limit for the value of $\%$ THDv is $5 \%$, so it can be said that the \% THDv G5 buildings meet the standard. As for the value $\%$ THDi on the G5 building SDP panel in the range of $10.95 \%$ (R-phase) - $14.38 \%$ (S-phase).

Power factor measured at the SDP panel of building G5 Universitas Muhammadiyah Yogyakarta to phase R, S, T measured 0.95, 0.93, $0: 58$. The value is above the standard value of which amounted to PLN 0.85. Unbalanced Voltage (unbalanced loads) can still be said to be safe because the IEEE standard limits defined for Unbalanced Voltage value is $2 \%$.

SDP panel measurement data Friday on May 25, 2018. Based on the results of measurements that have been made in the SDP panel, then using the average value of the parameters can be tabulated as Table 5 .

Based on the measured data on a Friday, SDP panel can be seen that the average voltage value is still within the limits permitted the limit up and down is $-10 \%$ and $+5 \%$ of the rated voltage of $220 \mathrm{~V}$ or between $198-231 \mathrm{~V}$ standards, where results measurement in the can that is $225.2 \mathrm{~V}$ on Rphase, $229 \mathrm{~V}$ at phase $\mathrm{S}$ and phase $\mathrm{T}$. While $230.5 \mathrm{~V}$ on the results of measurements of electrical current imbalance loads. This is indicated by the difference in current value large enough per-phase also the neutral current value on a scale approaching the value of current in phase $T$.

TABLE IV

\begin{tabular}{|c|c|c|c|c|c|}
\hline \multirow{2}{*}{ No. } & \multirow{2}{*}{ Parameter } & \multicolumn{4}{|c|}{ Thursday } \\
\hline & & Phase R & Phase S & Phase T & Neutral \\
\hline 1 & Frequency $(\mathrm{Hz})$ & & 49.9996 & & \\
\hline 2 & Voltage (V) & 225.3 & 229.7 & 231.2 & \\
\hline 3 & Voltage THD (\%) & 2.275 & 2.254 & 2.121 & \\
\hline 4 & Electric current (A) & 32.8 & 34.6 & 55.78 & 42.8 \\
\hline 5 & Electric current THD (\%) & 10.95 & 14.38 & 11.43 & \\
\hline 6 & Active Power (W) & 7004.7 & 7400.9 & 8224.6 & \\
\hline 7 & Reactive power (Var) & 2119 & 2743 & 8370.6 & \\
\hline 8 & Apparent power (VA) & 7328.7 & 7908.3 & 12771 & \\
\hline 9 & Power factor & 0.95 & 0.93 & 0.58 & \\
\hline 10 & V Unbalanced IEEE (\%) & & 1.49167 & & \\
\hline 11 & A Unbalanced IEEE (\%) & & 48575 & & \\
\hline
\end{tabular}


TABLE V

The Average Value Measurement of SDP Panel in G5 Building For Friday

\begin{tabular}{rlcccc}
\hline \hline \multirow{2}{*}{ No. } & Parameter & \multicolumn{4}{c}{ Friday } \\
\cline { 2 - 5 } & Phase R & Phase S & Phase T & Neutral \\
\hline 1 & Frequency (Hz) & \multicolumn{4}{c}{49.996} \\
2 & Voltage (V) & 225.2 & 229 & 230.5 & \\
3 & Voltage THD (\%) & 2.26 & 2.125 & 2.005 & \\
4 & Electric current (A) & 29.18 & 25.98 & 72.05 & 65.82 \\
5 & Electric current THD (\%) & 11.71 & 6.38 & 8.57 & \\
6 & Active Power (W) & 6284.3 & 5449.7 & 8821.02 & \\
7 & Reactive power (Var) & 1683 & 1977 & 13.547 & \\
8 & Apparent power (VA) & 6509.8 & 5814.3 & 16.596 & \\
9 & Power factor & 0.97 & 0.58 & 0.02 & \\
10 & V Unbalanced IEEE (\%) & & 1.33 & & \\
11 & A Unbalanced IEEE (\%) & & 84.155 & & \\
\hline \hline
\end{tabular}

TABLE VI

The Average Value Measurement of SDP PANel in G5 Building For SATURday

\begin{tabular}{rlcccc}
\hline \multirow{2}{*}{ No. } & \multicolumn{2}{|c}{ Parameter } & \multicolumn{4}{c}{ Saturday } \\
\cline { 3 - 6 } & & Phase R & Phase S & Phase T & Neutral \\
\hline 1 & Frequency (Hz) & 227.5 & 230019 & 233 & \\
2 & Voltage (V) & $2: 33$ & $2: 33$ & 2.1 & \\
3 & Voltage THD (\%) & $17: 56$ & 34 & 32.25 & 25.04 \\
4 & Electric current (A) & $12: 39$ & $15: 44$ & $11: 53$ & \\
5 & Electric current THD (\%) & 3713 & 7498.7 & 6799.5 & \\
6 & Active Power (W) & 1463 & 2383 & 3071 & \\
7 & Reactive power (Var) & 3995 & 7879.7 & 7476.9 & \\
8 & Apparent power (VA) & 0.93 & 0.95 & 0.9 & \\
9 & Power factor & & $1: 39$ & & \\
10 & V Unbalanced IEEE (\%) & & 46.97 & \\
11 & A Unbalanced IEEE (\%) & &
\end{tabular}

TABLE VII

The Average Value Measurement of SDP Panel in G5 Building for Sunday

\begin{tabular}{rlcccr}
\hline \hline \multirow{2}{*}{ No. } & \multicolumn{1}{c}{ Parameter } & Phase R & Phase S & Phase T & Neutral \\
\cline { 3 - 6 } & & & 49.9942 \\
& Frequency (Hz) & 230.9 & 235.4 & 235.9 & \\
2 & Voltage (V) & 2.375 & 2.25 & 2.138 & \\
3 & Voltage THD (\%) & 8817 & $23: 47$ & 15.95 & 20.87 \\
4 & Electric current (A) & 9529 & 15.68 & 13.6 & \\
5 & Electric current THD (\%) & 1893 & 5183 & 3215 & \\
6 & Active Power (W) & 764.3 & 1884 & 1890 & \\
7 & Reactive power (Var) & 2046 & 5536 & 3775 & \\
8 & Apparent power (VA) & 0.74 & 0.92 & 0.77 & \\
9 & Power factor & \multicolumn{5}{c}{1.35417} & & \\
10 & V Unbalanced IEEE (\%) & 56825 & \\
11 & A Unbalanced IEEE (\%) & \multicolumn{5}{c}{} \\
\hline \hline
\end{tabular}

TABLE VIII

The Power Losses of Each Phase R, S, AND T

\begin{tabular}{lcccccc}
\hline \hline \multirow{1}{*}{ Day } & \multicolumn{3}{c}{ OPLT } & \multicolumn{3}{c}{ WBP } \\
\cline { 2 - 7 } & Phase R & Phase S & Phase T & Phase R & Phase S & Phase T \\
\hline Monday & 6095 & 9725 & 9579 & 5977 & 10979 & 7577 \\
Tuesday & 7,458 & 1016 & 13,197 & 4815 & 7,651 & 6,169 \\
Wednesday & 7225 & 9677 & 13468 & 7026 & 9131 & 5409 \\
Thursday & 7955 & 9048 & 11,725 & 4982 & 6,670 & 15723 \\
Friday & 6,675 & 5,920 & 16430 & 5087 & 3,617 & 11,178 \\
Saturday & 4,890 & 8427 & 9473 & 3,466 & 9099 & 5,631 \\
Sunday & 1,881 & 5774 & 3,674 & 2,557 & 7227 & 3767 \\
\hline \hline
\end{tabular}


Harmonic disturbance that occurs on Friday can be seen in Table 5 where the value of $\%$ THDv and THDi on the SDP panel of the G5 building still meets the standard.

Power factor measured at the building SDP panel G5 Universitas Muhammadiyah Yogyakarta to phase R, S, T measured 0.97, 0:58, 0:02. The value is above the standard value of which amounted to PLN 0.85. Unbalanced Voltage (unbalanced loads) can still be said to be safe because the IEEE standard limits defined for Unbalanced Voltage value is $2 \%$.

SDP panel measurement data Saturday on May 19, 2018. Based on the results of measurements that have been made in the SDP panel, then using the average value of the parameters can be tabulated as Table 6.

Based on the measured data SDP panel on Saturday can be seen that the average voltage value is still within the limits permitted the limit up and down is $-10 \%$ and $+5 \%$ of the value of the standard voltage between $220 \mathrm{~V}$ or $198-231 \mathrm{~V}$, where the measurement results in to the $227.5 \mathrm{~V}$ on phase $\mathrm{R}$, $231.8 \mathrm{~V}$ at $\mathrm{S}$ phase and $233 \mathrm{~V}$ at phase Q. While on the results of measurements of electrical current imbalance loads. This is indicated by the difference in current value large enough per-phase also the neutral current value on a scale approaching the value of current in phase $T$.

Harmonic disturbance that occurs on Friday can be seen in Table 5 where the value of $\%$ THDv and THDi on the SDP panel of the G5 building still meets the standard.

Power factor measured at the building SDP panel G5 Universitas Muhammadiyah Yogyakarta to phase R, S, T measured 0.93, 0.95, 0.9. The value is above the standard value of which amounted to PLN 0.85. Unbalanced Voltage (unbalanced loads) can still be said to be safe because the IEEE standard limits defined for Unbalanced Voltage value is $2 \%$.

SDP panel measurement data Sunday on May 27, 2018. Based on the results of measurements that have been made in the SDP panel, then using the average value of the parameters can be tabulated as shown in Table 7.

Based on the measured data SDP panel on Sunday can be seen that the average voltage value is still within the limits permitted the limit up and down is $-10 \%$ and $+5 \%$ of the value of the standard voltage between $220 \mathrm{~V}$ or $198-231 \mathrm{~V}$, where the measurement results in to the $230.9 \mathrm{~V}$ on phase $\mathrm{R}$, 235.4V the $\mathrm{S}$ phase and the phase $235.9 \mathrm{~V} \mathrm{~T}$. While the results of measurements of electrical current imbalance loads. This is indicated by the difference in current value large enough per-phase also the neutral current value on a scale approaching the current value at $S$ phase.

Harmonic disturbance that occurred on Sunday can be seen in Table 7 where the value\% THDv the SDP panel G5 buildings in the range of $2: 14 \%$ (phase T) - 2:38\% (phase R). Based on the IEEE standards set a maximum limit for the value of $\%$ THDv is 5\%, so it can be said that the\% THDv G5 buildings meet the standard. As for the value $\%$ THDi on the G5 building SDP panel in the range of 9:53\% (phase R) - $15.68 \%$ (S phase). Based on the IEEE standards set value $\%$ THDi value should not exceed $15 \%$ this year, so we can say that $\%$ THDi G5 buildings meet the standard.

Power factor measured at the building SDP panel G5 Universitas Muhammadiyah Yogyakarta to phase R, S, T measured 0.74, 0.92, 0.77. The value is above the standard value of which amounted to PLN 0.85. Unbalanced Voltage (unbalanced loads) can still be said to be safe because the IEEE standard limits defined for Unbalanced Voltage value is $2 \%$.

\section{III.2. Calculation of Loss Loss Due to Unbalanced Power and Harmonics}

\section{Barriers Conductor}

Large cable barrier phase and neutral conductors of the same value which is equal to $0,193 \Omega / \mathrm{Km}$. Major obstacle cable conductor in accordance with the specifications of attached cables in the electrical installation supreme NYY cables per phase with an area of $95 \mathrm{~mm} 2$ with cable distances assuming the same transformer that is as far as $1 \mathrm{~km}$.

2. Calculation of Power Losses Each phase R, S, and $\mathrm{T}$

Calculation of Power Losses Each phase R, S, and $\mathrm{T}$ can use the following equation:

$$
\begin{aligned}
& \Delta P_{R}=\sum_{k=1}^{n} R p h \times I k_{R}^{2} \quad \text { (Power Losses Fasa } R \text { ) } \\
& \Delta P_{S}=\sum_{k=1}^{n} R p h \times I k_{S}^{2} \quad \text { (Power Losses Fasa S) } \\
& \Delta P_{T}=\sum_{k=1}^{n} \operatorname{Rph} x I k_{T}^{2} \quad \text { (Power Losses Fasa T) }
\end{aligned}
$$

Based on these equations are used to determine the power Losses per-phase $\mathrm{R}, \mathrm{S}$, and $\mathrm{T}$. where calculation results can be seen in Table 8 .
3. Calculation
of Power
Losses
in Neutral
Conductor
To determine the value of the power losses in the 
neutral conductor must first know the value of harmonic currents. After getting the harmonic current value then the next is to calculate Power Losses in the neutral conductor by using the following equation in order to obtain results that can be seen in Table 9 .

$$
\Delta P N=\sum_{k=1}^{25} x 0193 I k 2 \mathrm{~N}
$$

Based on calculations of power losses of each phase R, S, and T are also calculating power losses in the neutral conductor then can be the total value as shown in Table 10 and Table 11.

\section{III.3. Percentage calculations Power Losses}

Calculation of percentage of power losses compared to total active power consumed. Total active power that made reference is the average total active power on SDP panel Monday as tabulated in Table 12.

Calculation of percentage Power Losses:

$$
\text { percentage } \begin{aligned}
\Delta P & =\frac{\Delta \mathrm{P}}{P} x 100 \% \\
& =100 \% \frac{220.363+183.926}{23100.37} \\
& =1.75 \%
\end{aligned}
$$

So great value for power losses due to harmonics and unbalance is equal to $1.75 \%$ of the total use of the real power on the panel SDP.

TABLE IX

THE POWER Losses In THE NeUtRAL CONDUCTOR

\begin{tabular}{llcl}
\hline \hline \multicolumn{1}{c}{ Day } & $\begin{array}{l}\text { Neutral } \\
(\text { OPLT })\end{array}$ & $\begin{array}{l}\text { Neutral } \\
(\text { WBP })\end{array}$ & Units \\
\hline Monday & 3.658413 & 4.713053 & Watt \\
Tuesday & 9.463729 & 2.637521 & Watt \\
Wednesday & 5.852346 & 4.168861 & Watt \\
Thursday & 4.183857 & 11.50639 & Watt \\
Friday & 10.21271 & 7.642156 & Watt \\
Saturday & 4.353375 & 5.036386 & Watt \\
Sunday & 3.523887 & 4.484962 & Watt \\
\hline \hline
\end{tabular}

TABLE X

Rated POWER Losses Due to UnBalance AND HARMonics (OPLT)

\begin{tabular}{lrrrrrl}
\hline \hline \multicolumn{1}{c}{ Day } & Phase R & Phase S & Phase T & Neutral & Total & Units \\
\hline Monday & 6095 & 9725 & 9579 & 3,658 & 29.0577 & Watt \\
Tuesday & 7,458 & 10816 & 13197 & 9464 & 40.9352 & Watt \\
Wednesday & 7225 & 9677 & 13468 & 5852 & 36.2222 & Watt \\
Thursday & 7955 & 9048 & 11,725 & 4,184 & 32.9124 & Watt \\
Friday & 6,675 & 5,920 & 16430 & 1013 & 39.2379 & Watt \\
Saturday & 4,890 & 8427 & 9473 & 4,353 & 27.1444 & Watt \\
Sunday & 1,881 & 5774 & 3,674 & 3,524 & 14.8528 & Watt \\
Total & 42.1802 & 59.3883 & 77.5458 & 41.2483 & 220363 & Watt \\
\hline \hline
\end{tabular}

TABLE XI

RATED POWER LOSSES DUE TO UNBALANCE AND HARMONICS (WBP)

\begin{tabular}{lrrrrrl}
\hline \hline \multicolumn{1}{c}{ Day } & Phase R & Phase S & Phase T & Neutral & Total & Units \\
\hline Monday & 5977 & 1099 & 7577 & 4713 & 29.2453 & Watt \\
Tuesday & 4815 & 7,651 & 6,169 & 2,638 & 21.2729 & Watt \\
Wednesday & 7026 & 9131 & 5409 & 4,169 & 25.7346 & Watt \\
Thursday & 4982 & 6,670 & 1573 & 11,506 & 38.8815 & Watt \\
Friday & 5087 & 3,617 & 11,17 & 7642 & 27.5246 & Watt \\
Saturday & 3,466 & 9099 & 5,631 & 5036 & 23232 & Watt \\
Sunday & 2,557 & 7227 & 3767 & 4485 & 18.0355 & Watt \\
Total & 33.9096 & 54.3741 & 55.433 & 40.189 & 183926 & Watt \\
\hline \hline
\end{tabular}


TABLE XII

POWER ON MONDAY SDP PANEL

\begin{tabular}{lrrrr}
\hline \multicolumn{1}{c}{ Active Power } & Phase $\mathrm{R}$ & Phase S & Phase T & \multicolumn{1}{c}{ Total } \\
\hline MAX & 12743.04 & 13503.18 & 21710.99 & 47957.21 \\
MIN & 364.19 & 4555.56 & 1871.82 & 6791.57 \\
AVERAGE & 5605.895 & 9251.671 & 8242.803 & 23100.37 \\
\hline \hline
\end{tabular}

TABLE XIII

LARGE OPLT COSTS DUE TO POWER LOSSES

\begin{tabular}{lcrrrr}
\hline \hline \multicolumn{1}{c}{ Day } & Losses (Kw) & Losses /Day & Cost/Day & \multicolumn{1}{c}{ Cost/Month } & \multicolumn{1}{c}{ Cost/Year } \\
\hline Monday & 0029 & 0.5520965 & 20745.05 & 82980.18 & 995762.22 \\
Tuesday & 0041 & 0.7777686 & 29224.68 & 116898.74 & 1402784.86 \\
Wednesday & 0036 & 0.6882212 & 25859.94 & 103439.76 & 1241277.06 \\
Thursday & 0033 & 0.6253351 & 23496.99 & 93987.95 & 1127855.44 \\
Friday & 0039 & 0.745521 & 28012.98 & 112051.91 & 1344622.95 \\
Saturday & 0027 & 0.5157443 & 19379.11 & 77516.44 & 930197.33 \\
Sunday & 0015 & 0.2822039 & 10603.82 & 42415.28 & 508983.41 \\
& & & $\mathbf{R p ~ 7 3 2 2 . 5 7}$ & $\mathbf{R p} \mathbf{2 9 , 2 9 0 . 2 7}$ & $\mathbf{R p ~ 7 , 5 5 1 , 4 8 3 . 2 8}$ \\
\hline
\end{tabular}

TABLE XIV

THE WBP COSTS DUE TO POWER LOSSES

\begin{tabular}{lccccc}
\hline \hline \multicolumn{1}{c}{ Day } & Losses $(\mathrm{Kw})$ & Losses/Day & Cost/Day & Cost/Month & Cost/Year \\
\hline Monday & 0029 & 0.1462263 & 5494.46 & 21977.83 & 263734.02 \\
Tuesday & 0021 & 0.1063647 & 3996.66 & 15986.64 & 191839.64 \\
Wednesday & 0026 & 0.1286728 & 4834.89 & 19339.54 & 232074.51 \\
Thursday & 0039 & 0.1944077 & 7304.88 & 29219.50 & 350634.04 \\
Friday & 0028 & 0.1376228 & 5171.18 & 20684.72 & 248216.66 \\
Saturday & 0023 & 0.1161602 & 4364.72 & 17458.89 & 209506.71 \\
Sunday & 0018 & 0.0901775 & 3388.42 & 13553.69 & 162644.23 \\
Total & & & $\mathbf{R p ~ 3 4 , 5 5 5 . 2 0}$ & $\mathbf{R p ~ 1 3 8 , 2 2 0 . 8 2}$ & $\mathbf{R p ~ 1 , 6 5 8 , 6 4 9 . 8 1}$ \\
\hline \hline
\end{tabular}

\section{III.4. Calculation of Large Losses Due to Harmonic and Unbalanced}

Electricity Basic Tariff for Commercial Social Services with power above $200 \mathrm{kVA}$ limit included in fare classes S-3K / TM ie. PerkWH fee for this class is divided into two, namely the cost of PLT (peak load time) and cost OPLT (outside peak load time). Approximate calculation of the costs to be incurred every day, month and year as a result of power loss caused by harmonic distortion and unbalance load (imbalance load) as tabulated in Table 13.

Information:

Loses Cost per month:

$$
\begin{aligned}
& \text { PLT }=\text { Rp 2,794.84 } \\
& \text { OPLT }=\text { Rp 1,242.15 }
\end{aligned}
$$

Consideration of the day:

$$
\text { PLT }=5 \text { hours }
$$$$
\text { OPLT }=19 \text { hours }
$$

So that the total estimated cost that needs to be issued by the Universitas Muhammadiyah Yogyakarta as a result of power loss arising from harmonic distortion and imbalance loads for buildings G5 in 2018 amounted to:

Total Estimated $=$ Cost + Cost WBP OPLT

$$
=\operatorname{Rp} 7,551,483.28+\operatorname{Rp} 1,658,649.81
$$$$
=\operatorname{Rp} 9,210,133.09
$$

\section{III.5. Power Quality Improvement Solution}

Solutions that can reduce the cost of losses arising from harmonic distortion and imbalance loads are as follows:

1. Installation of capacitors that are reactive to a system that is inductive. Because if the theory that exists when the value of reactive power into smaller and remain active power value then the value of the apparent power will be small and cause large power factor value. If the capacitor is mounted better done rechecking the effectiveness, because there are still power factor value is lower than the standard required. The method can be suggested in the installation of compensation capacitor is sector namely by installing capacitors on SDP panel in each building.

2. Balancing the load on each phase of use, the more balanced the load on each phase then the 
current value at the neutral point will be reduced and power losses will be smaller.

3. Installation of passive filters on incoming and outgoing transformer to reduce the value of THD (Total Harmonic Distorsion). The closer to the burden of passive filter will work well especially non-linear load. Installation is expected to reduce the value of THD THD because the value can not be eliminated completely.

\section{Conclusion}

After doing the calculations and discussion of results of the analysis of a number of conclusions as follows:

1. Overall condition of the power quality in buildings G5 of Universitas Muhammadiyah Yogyakarta in pretty good shape.

2. Fluctuation value for the average voltage entirely still within safe limits specified, i.e., PLN is 198-231 Volt, the lowest voltage is 223.9 Volt and the highest is 235.9 Volt.

3 . An imbalance load on the system that caused the surge in neutral with the lowest value of 20.87 on the day of the week and the highest was 65.82 for the Friday.

4. Values for \%THDv still within safe limits IEEE 519-1992 tolerance is 5\% with the lowest percentage of $2,005 \%$, the highest $2.3875 \%$, as well as for the value of \% THDi also still within safe limits of tolerance, amounting to $15 \%$ with the lowest is $6.38 \%$ and the highest is $15.68 \%$.

5. There are several power factor value that is less than the standards that have been set by PLN namely, the T-phase on Thursday is 0.58 ; on the Friday, S-phase and T-phase are 0.58 and 0.02 , respectivaly; and on Sunday at the $\mathrm{R}$ phase and T-phase with each phase value of 0.74 and 0.77 .

6. Harmonic interference and load imbalance caused power losses in the system amounted to $1.75 \%$.

7. The total estimated cost of losses that have to be paid due to power losses caused by harmonic distortion and imbalance G5 load on the building in 2018 was Rp 9,210,133.09.

\section{Acknowledgments}

This work was supported by the Universitas Muhammadiyah Yogyakarta.

\section{References}

[1] T. Woolley, S. Kimmins, P. Harrison and R. Harrison, Green Building Handbook, New York: E \& FN Spon, 1997.

[2] T. Gönen, Electric Power Distribution System Engineering, Florida: CRC Press, 2008.

[3] Malik Sameeullah, Jitendra Kumar, Kanhaiya Lal, Jagdish Chander, "Energy Audit: A Case Study of Hostel Building", International Journal of Research in Management Science \& Technology, vol. 2, no. 2, August 2014.

[4] G. Dall'O', A. Speecher and E. Bruni, "The Green Energy Audit, a new procedure for the sustainable auditing of existing buildings integrated with LEED Protocols," Sustainable Cities and Society, vol. 3, pp. 54-65, 2012.

[5] Sandip Ballal, Energy Performance Important and Energy Cost Reductions at Baltic Place Commercial Office Complex, no. 1-64, February 2016.

[6] W. Priska, Arista, "Electrical Power Quality Audit DTETI UGM," Gajah Mada University, 2015.

[7] S. Ginting, Frederick, "The Effect of Neutral Harmonic Against the Flow Distribution Transformer (Application On RSU Sari Mutiara Medan)," North Sumatra University, 2013.

[8] E. Mulyana, "Measurement of Harmonics Voltage And Current Electricity Tick On Building Directorate of Education University of Indonesia," J. University Of Education Indonesia, 2018.

\section{Authors' information}

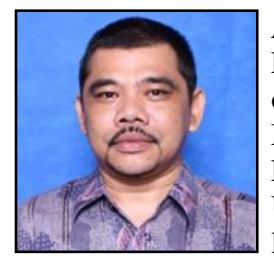

Agus Jamal obtained his B.Eng. in Electrical Engineering from the University of Gajah Mada, Indonesia in 1994. His Master study was done at 2010 at the Electrical Engineering, Gadjah Mada University, Indonesia. He currently is a lecture in the department of electrical engineering, University of Muhammadiyah Yogyakarta.

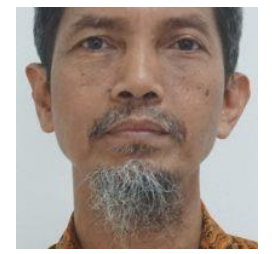

Slamet Suripto obtained his B.Eng. in Electrical Engineering from the University of Gajah Mada, Indonesia. His Master study was done at the Electrical Engineering, Gadjah Mada University, Indonesia. He currently is a lecture in the department of electrical engineering, University of Muhammadiyah Yogyakarta.

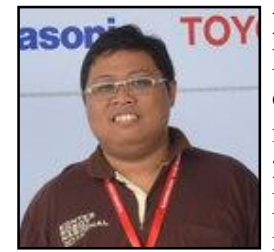

Rama Okta Wiyagi obtained his B.Eng. in Electrical Engineering from the University of Muhammadiyah Yogyakarta, Indonesia in 2009. His Master study was done at 2015 at the Electrical Engineering, Gadjah Mada University, Indonesia. He currently is a lecture in the department of electrical engineering, University of Muhammadiyah Yogyakarta. 
Dimas Bangkit Wijayanto obtained his B.Eng. in Electrical Engineering from the University of Muhammadiyah Yogyakarta, Indonesia in 2018.

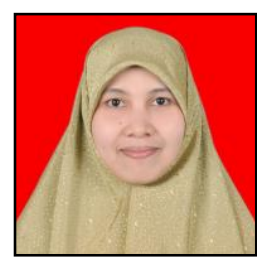

Yessi Jusman obtained her B.Eng. in Electrical and Electronic Engineering from Andalas University, Indonesia in 2007. She worked as a Research Assistant started in July 2008 until November 2009 in Universiti Sains Malaysia. Her Master study was done at 2012 at the School of Electrical and Electronic Engineering, USM Engineering Campus in Nibong Tebal, Penang, Malaysia. She was finished her Ph.D. degree in 2016 at the University of Malaya with specializes in Image, Signal Processing, and algorithms. She currently is a lecture in the department of electrical engineering, University of Muhammadiyah Yogyakarta.

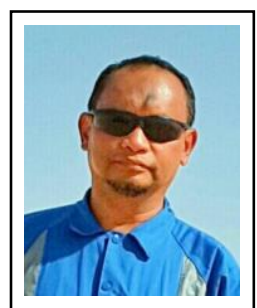

Teguh Iman Prasetyo hold a bachelor degree in 2000 from Electrical Engineering Department, Universitas Muhammadiyah Yogyakarta, Indonesia. Mr. Teguh Iman Prasetyo is currently a professional in Production on the Job Trainer and Competence Assessor, Petroleum Development Oman, Muscat, Sultanate of Oman. His main research interest is in control system and distributed control system. 